\title{
Crescimento pulmonar compensatório (CPC): massa corpórea, conteúdo protéico e massa pulmonares em ratos subnutridos trilobectomizados ${ }^{1}$
}

\author{
Raul Lopes Ruiz Júnior ${ }^{2}$, Lídia Raquel de Carvalho³, Antonio José Maria Cataneo ${ }^{4}$
}

\begin{abstract}
Ruiz Júnior RL, Carvalho LR, Cataneo AJM. Crescimento pulmonar compensatório (CPC): massa corpórea, conteúdo protéico e massa pulmonares em ratos subnutridos trilobectomizados. Acta Cir Bras [serial online] 2004 Mar-Abr;19(2). Disponível em URL: http://www.scielo.br/acb.

RESUMO - Objetivo: Avaliar o comportamento bioquímico do CPC após trilobectomia no rato adulto jovem subnutrido. Métodos: Foram utilizados 137 ratos "Wistar", machos, subnutridos pela oferta de 33\% da ingestão diária normal na fase de adaptação e durante o experimento, distribuídos por sorteio, em 9 grupos experimentais, submetidos a três tratamentos (Controle, Toracotomia, Trilobectomia) e sacrificados em três momentos (7, 30 e 90 dias). Na Trilobectomia foram extirpados os lobos médio, acessório e caudal direitos, que representavam $55 \%$ do tecido pulmonar. Estudouse os seguintes atributos e variáveis: massa corpórea e pulmonar, relação entre massa pulmonar e corpórea e conteúdos protéicos pulmonares. Resultados: No lobo cranial e no pulmão esquerdo, tanto a massa quanto os conteúdos protéicos, nos trilobectomizados, foram maiores em todos os momentos do estudo quando comparados aos demais, sendo este aumento suficiente para compensar a perda dos três lobos. Os conteúdos protéicos do lobo cranial e do pulmão esquerdo, nos trilobectomizados, tiveram o mesmo comportamento da massa pulmonar, mas este aumento não foi suficiente para compensar a perda dos três lobos. Conclusões: Nos ratos adultos subnutridos trilobectomizados ocorre CPC. A recuperação da massa pulmonar é total, mas o conteúdo protéico pulmonar apesar de aumentar, não chega aos valores dos ratos não trilobectomizados.
\end{abstract}

DESCRITORES - Pulmão/crescimento. Transtornos nutricionais. Ratos Wistar.

\section{Introdução}

Tanto o CPC como o crescimento fisiológico são expressões do conteúdo tecidual de proteínas que variam em função do equilíbrio entre as taxas de síntese e degradação ${ }^{1}$.

Mudanças nas taxas de degradação ou síntese de colágeno, proteína estrutural que representa de $15-20 \%$ da proteína pulmonar, além de outras proteínas, têm papel relevante no $\mathrm{CPC}^{1}$. A taxa de síntese protéica pode ser influenciada por vários mecanismos, sendo um deles as alterações na dieta ${ }^{2,3}$. Estudo de nutrição animal, utilizando porcos machos e fêmeas, demonstrou que o ganho em massa corpórea, bem como em massa pulmonar, estiveram acelerados quando os animais foram submetidos a um período de restrição nutricional, sendo depois realimentados com diferentes concentrações de proteína na dieta ${ }^{3}$. Esta resposta compensatória foi observada nos pulmões, porém em outros órgãos que apresentam grande atividade metabólica como o fígado, rins e trato gastrintestinal, a restrição alimentar reduziu a massa destes ${ }^{4}$. Ocorreram modificações na composição corpórea desses animais, que apresentaram carcaças com menor teor de gordura ${ }^{3}$. Em trabalho anterior mostramos que o CPC ocorre rapidamente em ratos nutridos, teríamos este mesmo comportamento nos ratos subnutridos?

\section{Objetivo}

Investigar o comportamento bioquímico do CPC após a trilobectomia pulmonar no rato jovem, subnutrido, através da dosagem dos conteúdos pulmonares de proteínas e das análises da massa corpórea e do parênquima pulmonar remanescente, em três momentos evolutivos do pós-operatório.

\section{Métodos}

Foram utilizados 137 ratos "Wistar", machos, sadios, com peso aproximado de $175 \mathrm{~g}$ e 75 dias de idade, mantidos durante todo o estudo em sala fechada, com iluminação artificial, por 12 horas diárias, alojados individualmente em gaiolas de metal onde receberam apenas $10 \mathrm{~g}$ de ração por dia e tiveram livre acesso à água durante todo o experimento. Ficaram em jejum nas 24 horas que precederam ao ato anestésico-cirúrgico. Este estudo foi aprovado pelo Conselho de Ética em Experimentação Animal (CEEA) da Faculdade de Medicina de Botucatu - UNESP.

1. Trabalho realizado na Disciplina de Cirurgia Torácica do Departamento de Cirurgia e Ortopedia da Faculdade de Medicina de Botucatu - UNESP.

2. Professor Assistente da Disciplina de Cirurgia Torácica do Depto. de Cirurgia e Ortopedia da Faculdade de Medicina de Botucatu-UNESP.

3. Professor Assistente do Depto. de Bioestatística do Instituto de Biociências da UNESP.

4. Prof. Adjunto da Disciplina de Cirurgia Torácica do Depto. de Cirurgia e Ortopedia da Faculdade de Medicina de Botucatu-UNESP. 
Iniciando o período de adaptação, que teve a duração de 14 dias, os ratos foram pesados, examinados, e a partir deste instante, foi controlada a quantidade de ração que recebiam diariamente.

Estudo piloto demonstrou que cada rato normal, nesta fase de crescimento, ingeria cerca de $30 \mathrm{~g}$ de ração Labina ${ }^{\circledR *}$ por dia. De acordo com este modelo de subnutrição, durante a fase de adaptação, os animais passaram a receber diariamente apenas 33\% da quantidade de ingestão diária de um rato normal, cerca de $10 \mathrm{~g}$. O mesmo tratamento nutricional foi oferecido por todo o período que durou o experimento.

Após um período inicial de 14 dias, observou-se que os animais apresentaram sinais de subnutrição (redução no ganho ponderal). Então, os animais foram distribuídos, por sorteio, em 9 grupos experimentais, e submetidos a três tipos de tratamento (Nenhum $=\mathbf{C O N}$, Toracotomia $=\mathbf{T O R}$, Trilobectomia $=$ TRI) e sacrificados em 3 diferentes momentos (7, 30 e 90 dias) com coleta de material para dosagem dos conteúdos de Proteínas em três diferentes amostras de tecido pulmonar: A - Parênquima do Pulmão Esquerdo; B - Parênquima do Lobo Cranial, e C - pool dos Lobos Acessório, Médio e Caudal.

Os grupos experimentais foram assim constituídos: controle aos 7, 30 e 90 dias, com 11,15 e 13 animais respectivamente. Nos grupos toracotomia e trilobectomia, nos mesmos momentos, com respectivamente, 20, 18, 14; e 14, 14 e 18 ratos.

Os animais foram submetidos à anestesia geral com injeção intraperitoneal de pentobarbital sódico (30mg/kg peso).

A manutenção das vias aéreas foi obtida através de intubação orotraqueal com tubo de polietileno PE160, de $8,2 \mathrm{~cm}$ de comprimento, com o auxílio de lâminas dobradas em "L" e fonte de luz fria.

A ventilação foi efetuada manualmente, por meio de AMBU (Automatical Mannual Breathing Unit).

Em condições de limpeza (tricotomia e álcool iodado) a trilobectomia foi então realizada através de uma toracotomia ampla no sétimo espaço intercostal direito. Após, seguiu-se à individualização do pedículo bronco-vascular do Lobo Caudal, que foi ligado com fio de algodão $\mathrm{n}^{\circ} 10 \mathrm{em}$ bloco. O mesmo procedimento foi realizado para os Lobos Médio e Acessório. A

trilobectomia deixa intacto o pulmão esquerdo que corresponde a $34 \%$ do volu-

me pulmonar e o lobo cranial que corresponde a $11 \%$ (Figura 1 ).

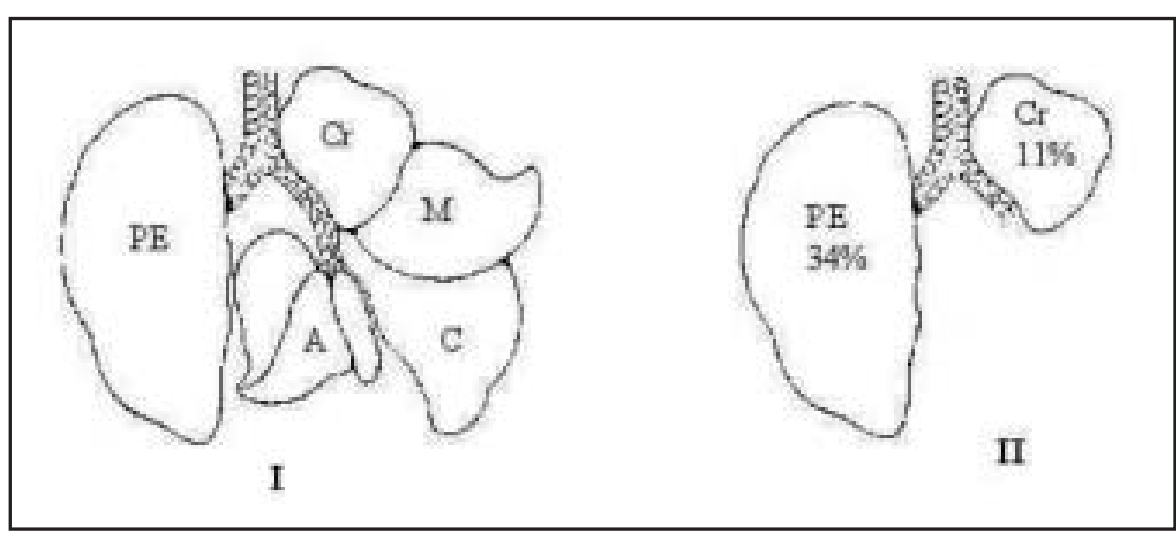

FIGURA 1 - I) Anatomia lobar dos pulmões do rato: A = lobo acessório, $\mathrm{C}=$ lobo caudal, $\mathrm{Cr}=$ lobo cranial, $\mathrm{PE}=$ pulmão esquerdo, $\mathrm{M}=$ lobo médio. II) Trilobectomia, porcentagem de parênquima pulmonar remanescente: $\mathrm{PE}=$ pulmão esquerdo $(34 \%)$; $\mathrm{Cr}=$ lobo cranial $(11 \%)$.

O fechamento da parede torácica foi realizado em três planos, com hiperinsuflação do pulmão remanescente no último ponto do plano muscular para retirada do ar da cavidade pleural. Os três planos, costal, muscular e cutâneo, foram fechados com pontos contínuos de fio de algodão ${ }^{\circ} 10$. No momento do sacrifício, após a pesagem dos ratos, estes foram anestesiados, como descrito anteriormente. A seguir realizouse laparotomia para sangria do animal pela secção da veia cava inferior e aorta abdominal. Por esternotomia mediana foi feita ressecção, em bloco, do coração e pulmões, sendo os últimos dissecados cuidadosamente, pesados em balança analítica e utilizados para determinação do conteúdo protéico, através do Nitrogênio Total, pelo Método de Micro-Kjldahl (1965).

Foram estudados os seguintes atributos e suas respectivas unidades: massa corpórea (g) do rato, no início da fase de adaptação; no tratamento e sacrifício. No lobo cranial, pulmão esquerdo e pulmão direito, isolados, estudou-se a massa (mg) e o conteúdo protéico $(\mathrm{mg})$. A soma dos valores do pulmão esquerdo e pulmão direito, nos grupos controle (CON) e toracotomia (TOR), ou pulmão esquerdo e lobo cranial no grupo trilobectomia (TRI), foram chamados respectivamente de Massa (mg) e Conteúdo Protéico (mg) dos pulmões.

Para o tratamento estatístico das variáveis que apresentaram distribuição normal, efetuou-se a Análise de Variância para Fatorial Inteiramente Aleatorizado ${ }^{6}$ com os fatores: $\mathrm{A}=$ tratamento: $\mathrm{CON}$; TOR; TRI;
$\mathrm{B}=$ tempo: $\mathrm{A}: \operatorname{aos} 7$ dias; $\mathrm{B}:$ aos 30 dias; $\mathrm{C}$ : aos 90 dias.

Em todas as hipóteses testadas, as estatísticas F calculadas foram consideradas significativas quando $p<0,05$. Os contrastes entre pares de médias foram verificados pelo método de Tukey com o cálculo da diferença mínima significativa (dms) para $\mathrm{a}=0,05$.

Para as variáveis que não apresentaram distribuição normal, foi utilizado o teste não-paramétrico de Kruskal-Wallis, seguido do teste de Dunn, para comparação dos grupos dentro de cada momento e para a comparação dos momentos dentro de cada grupo ${ }^{7}$.

\section{Resultados}

\section{Massa Corpórea}

Os ratos foram admitidos com peso aproximado de $175 \mathrm{~g}$ e após o período de adaptação de 14 dias perderam peso chegando a aproximadamente 140 a $150 \mathrm{~g}$, sendo então realizados os tratamentos. Não houve diferença significativa do peso entre os três grupos na admissão ou no período de adaptação.

Até os 7 dias após os tratamentos os ratos ainda perderam peso, chegando a aproximadamente $120 \mathrm{~g}$, quando então, começaram a ganhar peso normalmente chegando a aproximadamente $150 \mathrm{~g}, 90$ dias após os tratamentos. O comportamento da massa corpórea nos 3 grupos foi semelhante, não havendo diferença significativa entre eles em cada um dos momentos estudados (Figura 2). 


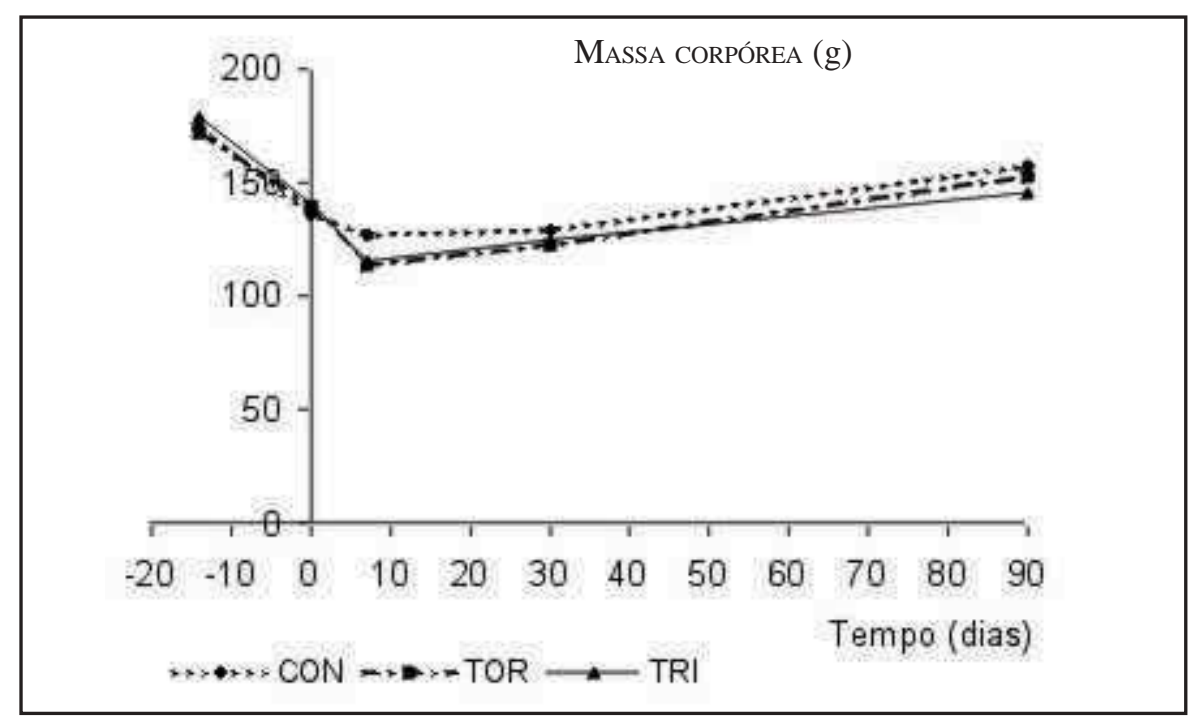

FIGURA 2 - Massa Corpórea (g) durante todo o experimento. Tratamento: $\mathrm{F}=1,83 ; \mathrm{p}>0,05$; $(\mathrm{CON}=\mathrm{TOR}=\mathrm{TRI})$.

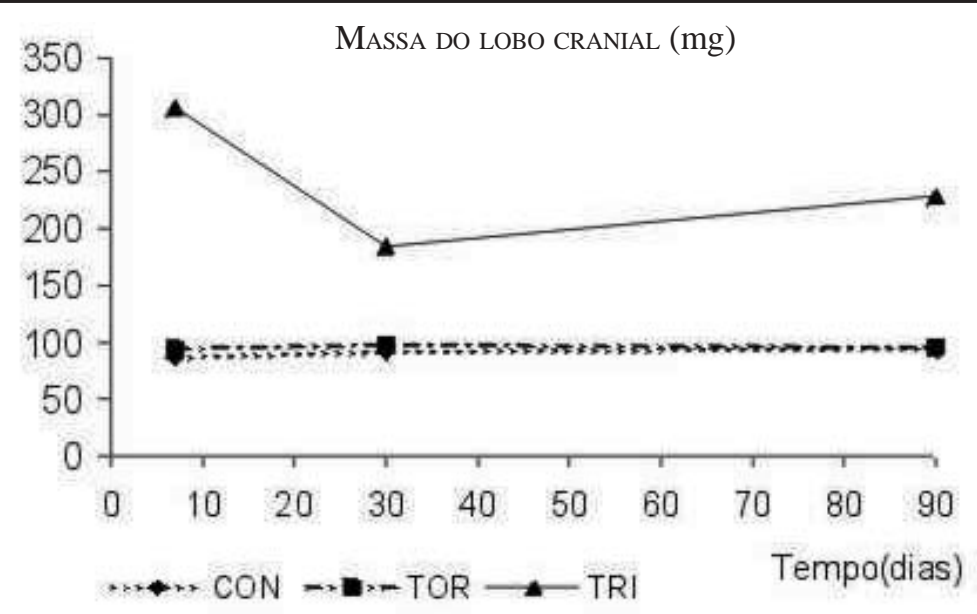

FIGURA 3 - Massa do lobo cranial (mg). Tratamento: F = 83,10; p < 0,05; (CON = TOR) $<$ TRI

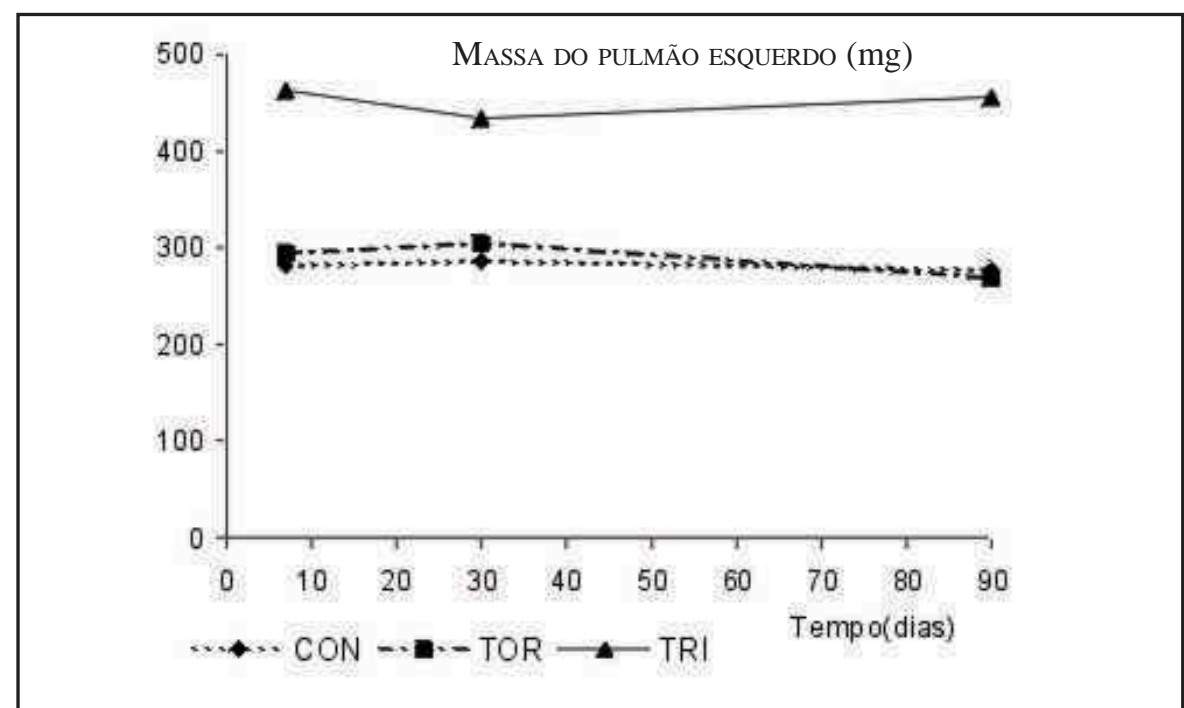

FIGURA 4 - Massa do pulmão esquerdo (mg). Tratamento: $\mathrm{F}=47,01 ; \mathrm{p}<0,05 ;(\mathrm{CON}=\mathrm{TOR})<$ TRI.

\section{Massa Pulmonar}

Quando foram comparadas as massas pulmonares dos lobos craniais e pulmões esquerdos, isoladamente, entre os grupos, observamos que foram significativamente maiores nos ratos trilobectomizados em todos os momentos do estudo (Figuras 3 e4).

Quando foram comparadas as massas dos pulmões direitos, estas foram significativamente menores nos ratos trilobectomizados em todos os momentos do estudo, pois, nestes só restou o lobo cranial, que apesar de ser maior que nos outros grupos não foi suficiente para compensar a perda dos três lobos (Figura 5).

Quando foram comparadas as massas pulmonares de ambos os pulmões não houve diferença significativa entre o grupo trilobectomizado e o controle em todos os momentos estudados, mostrando que o crescimento do pulmão esquerdo e do lobo cranial foram suficientes para suprir a perda dos três lobos (Figura 6).

\section{Relação entre a Massa Pulmonar e a Massa Corpórea}

A relação entre a massa pulmonar e a massa corpórea, nos ratos trilobectomizados, foi sempre menor do que nos demais grupos (Figura 7), mas esta diferença não foi significativa em todos os momentos.

\section{Conteúdo Protéico}

O conteúdo protéico do lobo cranial e do pulmão esquerdo tiveram o mesmo comportamento das massas, sendo significativamente maiores nos ratos trilobectomizados (Figuras 8 e 9).

No pulmão direito, semelhante à massa, $\mathrm{o}$ conteúdo protéico também foi menor nos ratos trilobectomizados, mostrando que o aumento no lobo cranial não foi suficiente para compensar a perda dos outros 3 lobos à direita (Figura 10). Quando se compara o conteúdo protéico de ambos os pulmões, nota-se que foi significativamente menor nos ratos trilobectomizados, mostrando que ao contrário da massa, $\mathrm{o}$ aumento nos lobos cranial e pulmão esquerdo não foram suficientes para compensar a perda dos três lobos (Figura 11). 


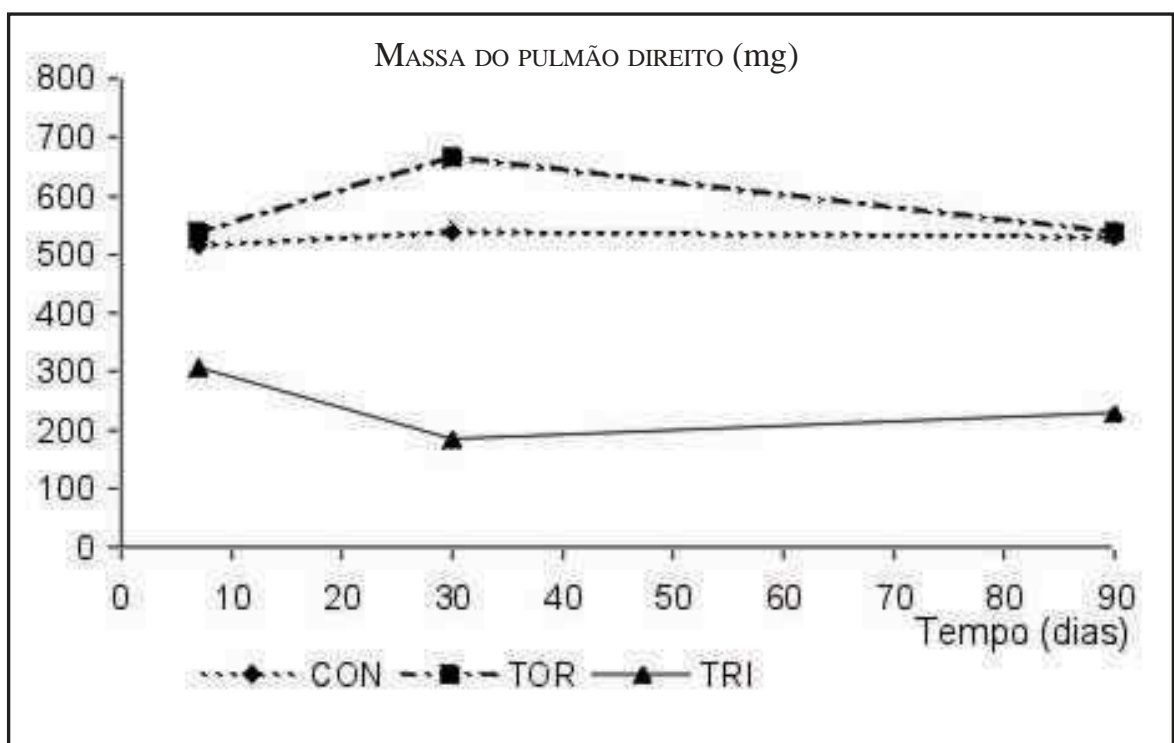

FIGURA 5 - Massa do pulmão direito (mg). Tratamento: $\mathrm{F}=31,05 ; \mathrm{p}<0,05 ;(\mathrm{CON}=\mathrm{TOR})>\mathrm{TRI}$.

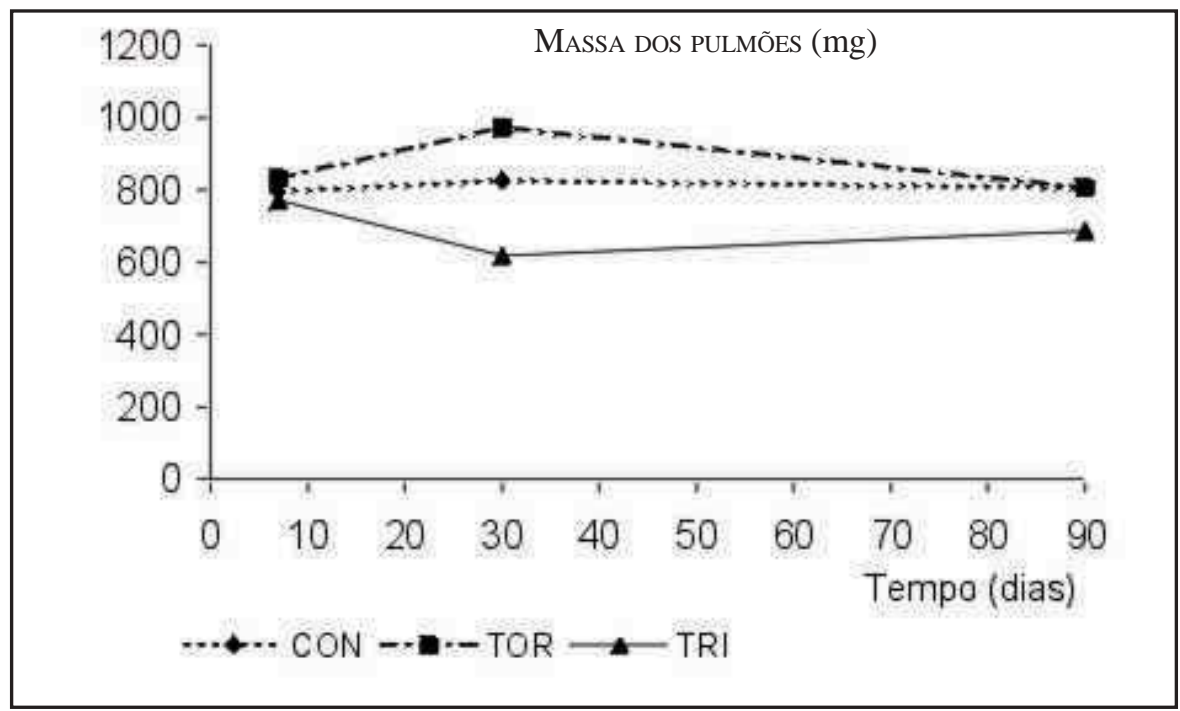

FIGURA 6 - Massa dos pulmões (mg). Tratamento: $\mathrm{F}=4,91 ; \mathrm{p}<0,05 ; \mathrm{CON}=$ TRI.

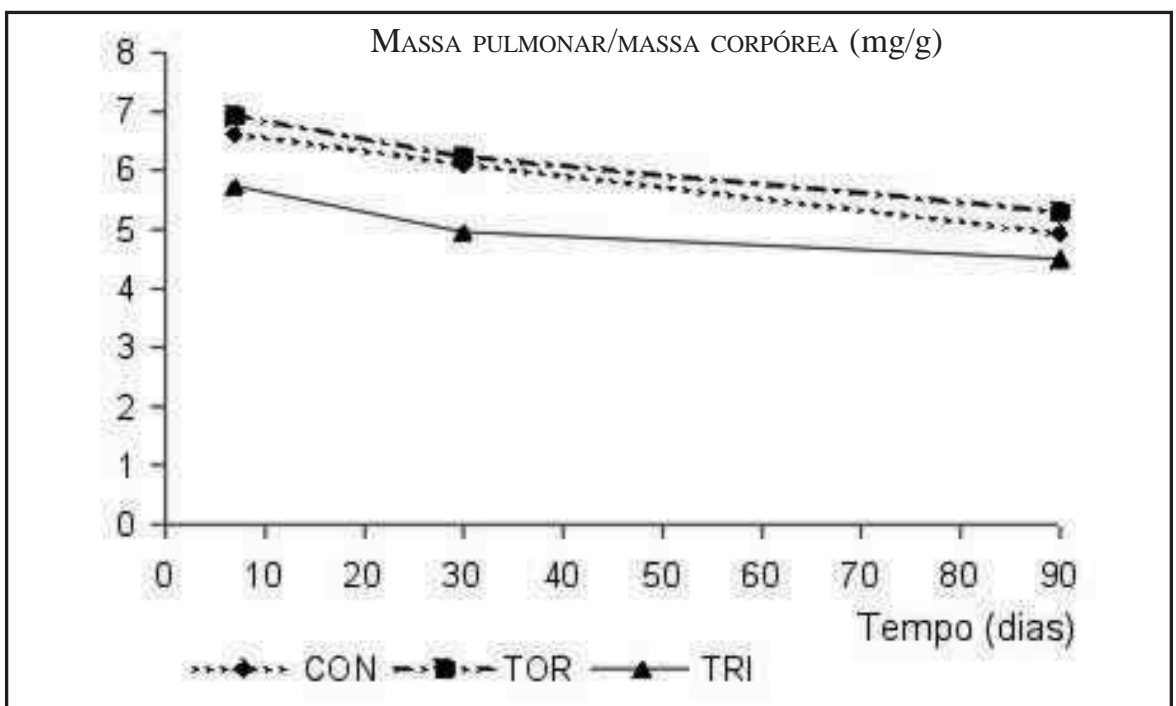

FIGURA 7 - Relação entre a massa pulmonar e a massa corpórea (mg/g). Tratamento: em 7 e 90 dias, $\mathrm{CON}=$ TRI; em 30 dias, $\mathrm{CON}>$ TRI.

\section{Discussão}

\section{Massa Corpórea}

Tanto nos ratos toracotomizados como nos trilobectomizados, no momento do sacrifício, a massa corpórea não apresentou diferença significativa quando comparada aos do grupo controle. Assim, tanto a toracotomia quanto a trilobectomia não tiveram interferência sobre este atributo em qualquer dos momentos estudados (Figura 2).

Vários estudos da literatura que utilizaram ratos nutridos observaram menor massa corpórea nos momentos mais iniciais após a ablação pulmonar, a qual levou à não recuperação desta nos momentos mais $\operatorname{tardios}^{5,9,10}$.

Neste estudo, observamos que em todos os grupos com a restrição da quantidade de alimento houve perda de massa corpórea nos momentos iniciais, até que os ratos se adaptassem a esta nova situação nutricional, o que ocorreu entre o momento do tratamento e os 30 dias, sendo que neste último momento a curva já era ascendente em todos os grupos (Figura 2).

Acredita-se que a perda de massa corpórea ocorreu devido à queima de gordura desde o início da subnutrição até o momento da adaptação, havendo neste período, portanto, um catabolismo bem maior que o anabolismo. Em estudos anteriores, foi demonstrado que o catabolismo superava o anabolismo nos primeiros 7 dias após a trilobectomia ${ }^{5}$, período em que os ratos trilobectomizados perderam massa corpórea e não mais a recuperaram. Neste estudo parece que o incremento do catabolismo foi mais às custas da restrição de alimentos do que da agressão operatória, mascarando assim esse efeito. Houve uma tendência dos ratos do grupo controle ter massa corpórea maior que dos grupos operados, mas em nenhum momento foram significativos. Por outro lado a agressão da trilobectomia não foi menor que a da toracotomia isolada (Figura 2).

\section{Massa dos Pulmões}

A massa do lobo cranial foi sempre maior nos ratos trilobectomizados em todos os momentos estudados, variando este incremento de 2 a 3,5 vezes (Figura 3), mas este aumento não foi suficiente para compensar a perda dos 3 lobos no pulmão 


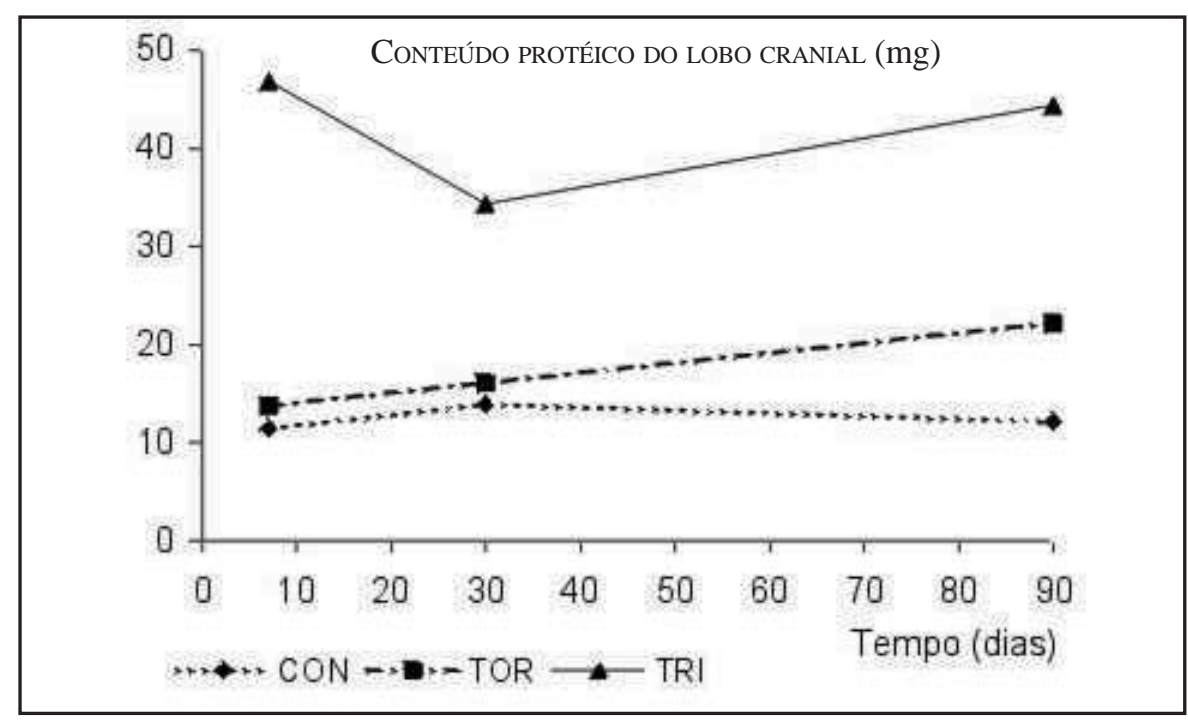

FIGURA 8 - Conteúdo Protéico do lobo cranial $(\mathrm{mg})$. Tratamento: $\mathrm{p}<0,05 ;(\mathrm{CON}=\mathrm{TOR})<\mathrm{TRI}$.

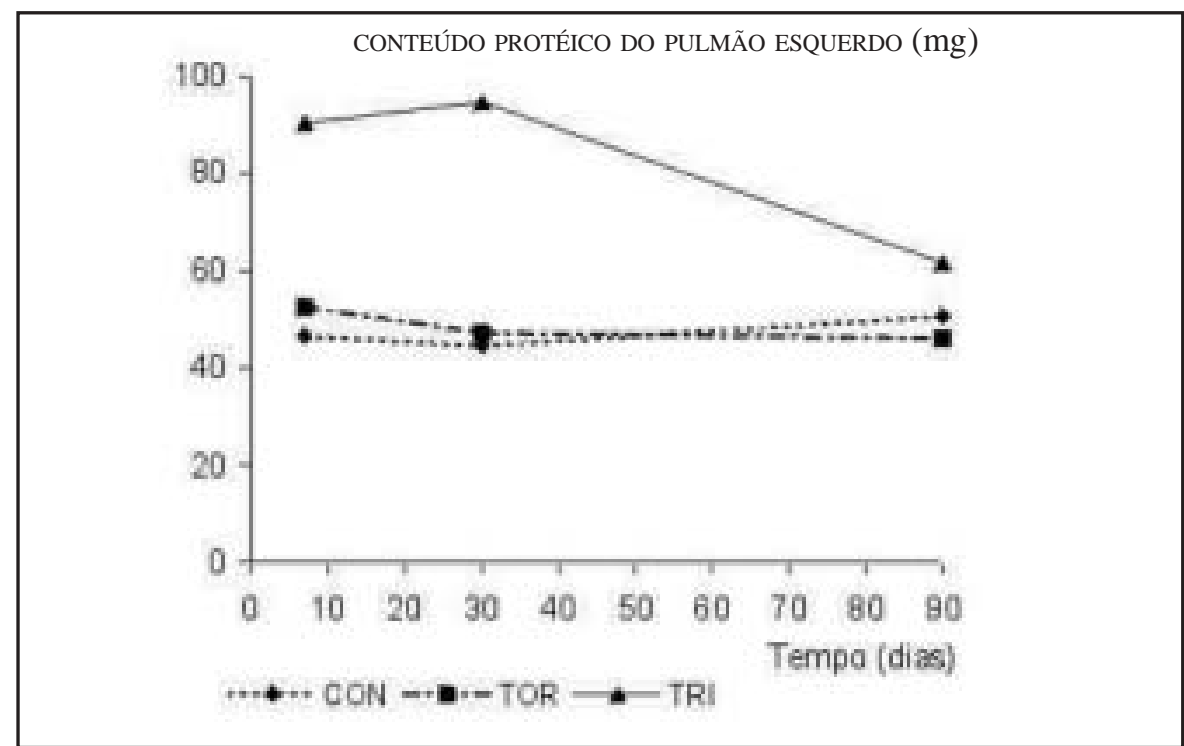

FIGURA 9 - Conteúdo Protéico do pulmão esquerdo (mg). Tratamento: $\mathrm{p}<0,05 ;(\mathrm{CON}=\mathrm{TOR})<$ TRI.

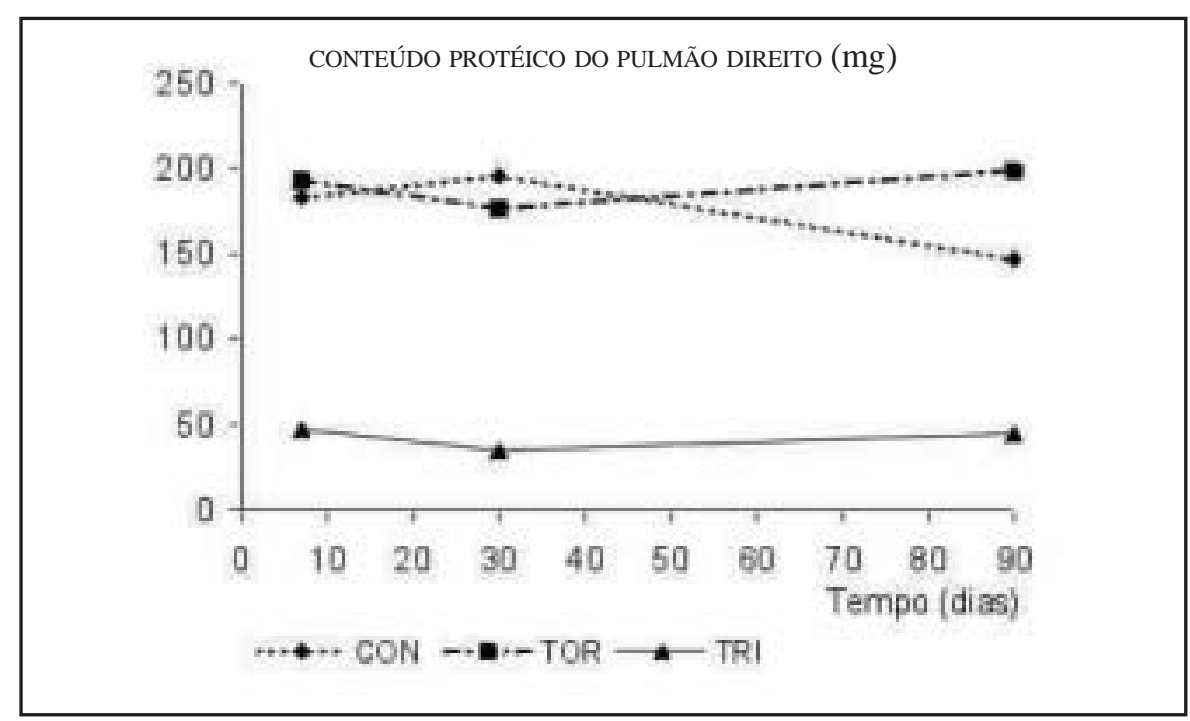

FIGURA 10 - Conteúdo Protéico do pulmão direito $(\mathrm{mg})$. Tratamento: $\mathrm{p}\langle 0,05 ;(\mathrm{CON}=\mathrm{TOR})\rangle$ TRI. direito, pois se compararmos o pulmão direito entre os 3 grupos (Figura 5) veremos que os ratos do grupo trilobectomia, por só possuírem o lobo cranial à direita, tiveram suas massas significativamente menores que os demais em todos os momentos estudados. Este incremento da massa do lobo cranial no momento inicial relaciona-se com a primeira fase do $\mathrm{CPC}$, que é mais rápida, precoce e com predomínio do crescimento celular hipertrófico $^{10,11}$, acreditando-se ocorrer devido a necessidade de ocupação do espaço pleural prontamente, após a trilobectomia. Em ratos nutridos este fenômeno continua ocorrendo após este momento, mas em menor velocidade ${ }^{10}$. No presente estudo o crescimento do lobo cranial ocorreu agudamente e depois, além de não mais crescer, parece ter reduzido (Figura 3), levando-nos a imaginar que logo após a trilobectomia deva ter ocorrido algum estímulo maior ao CPC, semelhante ao que ocorre com o rato nutrido. Enquanto nestes últimos o estímulo continua, no rato subnutrido este estímulo parece desaparecer. Tanto nos ratos nutridos como nos subnutridos este crescimento agudo parece ser estimulado pelo estiramento do parênquima pulmonar remanescente à direita devido à queda da pressão pleural, decorrente da ressecção da maior parte do parênquima pulmonar daquele lado.

A massa do pulmão esquerdo, nos ratos trilobectomizados, foi sempre maior em todos os momentos estudados, sendo aproximadamente 1,5 vezes maior que nos demais grupos (Figura 4). Talvez o crescimento proporcionalmente menor que no lobo cranial se deva ao pequeno espaço que o desvio do mediastino para a direita propiciou, na tentativa de reduzir a cavidade pleural direita, ocupando o espaço deixado pela trilobectomia e, conseqüentemente, aumentando um pouco à esquerda. Porém o pulmão esquerdo é grande e rapidamente consegue preencher a cavidade pleural, por isso cresceria proporcionalmente menos que o lobo cranial e desta forma ocorreria um pequeno estiramento do parênquima pulmonar remanescente. Este CPC já é evidente aos 7 dias após a trilobectomia, e semelhantemente ao lobo cranial também não aumenta mais nos outros momentos.

Observamos que a massa dos pulmões dos ratos trilobectomizados não foi signi- 


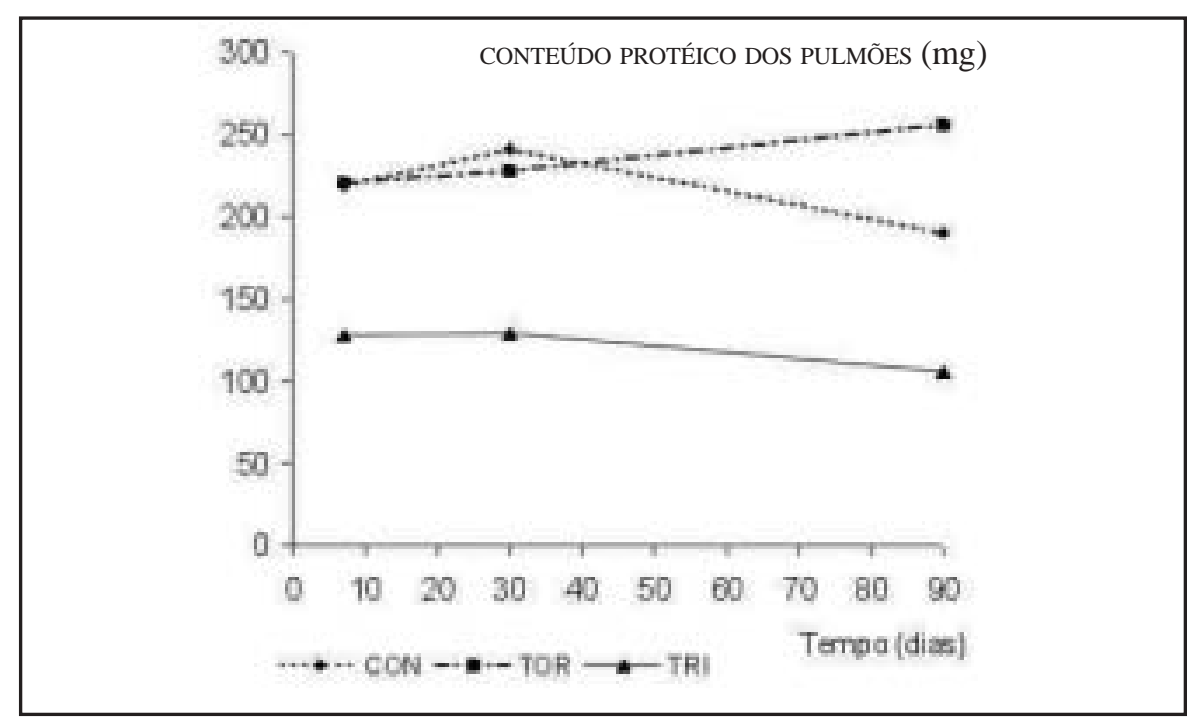

FIGURA 11 - Conteúdo Protéico dos pulmões (mg). Tratamento: $p<0,05$; $($ CON $=$ TOR) $>$ TRI.

ficativamente diferente à dos demais grupos, apesar de ter sido ressecado $55 \%$ dos pulmões, mostrando que o CPC evidenciado no lobo cranial e pulmão esquerdo foram suficientes para recuperar a massa de todo o parênquima pulmonar em todos os momentos estudados (Figura 6). Ocorreu a recuperação desta variável apesar da redução quantitativa do padrão alimentar a que foram submetidos os ratos, semelhante ao que ocorreu em estudo realizado anteriormente com ratos nutridos $5,9,10$.

\section{Relação entre a Massa dos Pulmões e a Massa Corpórea}

A relação entre a massa dos pulmões e a massa corpórea no momento do sacrifício foi menor nos ratos trilobectomizados, mas nem sempre esta diferença foi significativa quando comparados aos demais grupos, sugerindo que a massa pulmonar foi recuperada, mas não totalmente (Figura 7).

Nos ratos trilobectomizados, houve redução de $55 \%$ em massa pulmonar, ocasionada pela ressecção dos lobos médio, caudal e acessório. Se não houvesse um crescimento compensatório rápido do pulmão remanescente, a relação entre a massa pulmonar e a massa corpórea seria, nos ratos trilobectomizados, aproximadamente a metade quando comparada à encontrada nos demais grupos, mas pudemos observar que chegou a ser mais de $80 \%$.

Talvez não tenha chegado próximo de $100 \%$ devido ao fato observado em estudo demonstrando que em ratos não ressecados, submetidos à privação total de alimentos por 72 horas, que a perda de massa corpórea foi maior do que a perda de massa pulmonar, propiciando um incremento na relação entre a massa dos pulmões e a massa corpórea ${ }^{12}$. Este fato levaria a um distanciamento muito maior entre o grupo de ratos subnutridos trilobectomizados que teriam esta relação reduzida, enquanto que nos demais não ressecados, teriam-na aumentada.

\section{Proteína}

A análise do conteúdo protéico no lobo cranial representou a evidência de que o CPC manifestou-se através de uma resposta bastante intensa neste lobo. Nos ratos trilobectomizados este parâmetro foi sempre maior quando comparado ao dos outros grupos em todos os momentos estudados (Figura 8). Embora a intensidade da resposta em crescimento tenha sido muito evidente, este incremento não foi suficiente para compensar a perda dos lobos extirpados, pois o conteúdo protéico no pulmão direito dos ratos trilobectomizados, os quais só possuíam o lobo cranial, foi sempre menor que nos demais grupos em todos os momentos estudados (Figura 10).

Em estudo anterior, utilizando ratos jovens nutridos submetidos a trilobectomia, o conteúdo protéico dos pulmões direitos, foi sempre menor nos trilobectomizados, mostrando também que o lobo cranial sozinho não foi suficiente para compensar a perda dos outros lobos daquele mesmo lado $^{9,13}$.

No pulmão esquerdo vemos que o conteúdo protéico nos ratos trilobectomizados foi sempre maior quando comparado ao dos demais em todos os momentos do estudo (Figura 9).

O conteúdo protéico nos pulmões, somatória entre os pulmões direito e esquerdo, foi sempre menor nos ratos trilobectomizados quando comparados ao dos demais grupos em todos os momentos estudados (Figura 11). Portanto o CPC após a trilobectomia, apesar de evidenciado no lobo cranial e no pulmão esquerdo, foi insuficiente para suprir a perda desta variável. Tais resultados não são comparáveis aos encontrados em estudo que utilizamos ratos jovens nutridos trilobectomizados, pois nestes houve a recuperação total desta variável $^{9,13}$.

Estudos que utilizaram grupos de ratos nutridos adultos submetidos à ressecção pulmonar, demonstraram que os pulmões dos ratos adultos podem ser capazes de coordenar a proliferação celular e produção de componentes protéicos da matriz extracelular. Tanto a divisão celular quanto a produção destes componentes protéicos são acompanhadas pelo incremento do volume nos espaços aéreos terminais, sendo assim mantida a morfologia normal do parênquima pulmonar remanescente submetido ao $\mathrm{CPC}^{14}$. Neste nosso estudo, parece que o déficit nutricional foi o fator limitante da ocorrência de todos estes fenômenos, pela simples falta de substrato protéico, reduzido na dieta.

\section{Conclusões}

Concluímos que nos ratos subnutridos houve CPC. Nos trilobectomizados a recuperação da massa pulmonar chegou a valores semelhantes aos que não foram submetidos à ressecção pulmonar.

Quanto ao conteúdo protéico, apesar de ter ocorrido o crescimento compensatório no lobo remanescente e no pulmão contralateral, este não foi suficiente para atingir os valores dos grupos não extirpados. Esta é a grande diferença quando comparamos este resultado ao obtido com os ratos nutridos, onde não encontramos diferença significativa entre os ratos trilobectomizados e os demais grupos. 


\section{Referências}

1. Mcanulty RJ, Staple LH, Guerreiro D. Extensive changes in collagen synthesis and degradation during compensatory lung growth. Am J Physiol 1988; 255:C754-9.

2. Thomaz THA, Burini RC. Captação e utilização de substratos pelo pulmão. Homeostase energética nas condições de alimentação e de jejum. J Pneumol 1982; 8:107-12.

3. Critser DJ, Miller PS, Lewis AJ. The effect of dietary protein concentration on compensatory growth in barrows and gilts. J Anim Sci 1995; 73:3376-83.

4. Burrin DG, Britton RA, Ferrell CL. Visceral organ size and hepatocyte metabolic activity in fed and fasted rats. J Nutr 1988; 118:1547-52
5. Cataneo AJM, Curi PR, Reibscheid SM. Alterações morfológicas do aparelho respiratório pós-trilobectomia pulmonar: estudo experimental no rato. J Pneumol $1988 ; 14: 121-6$.

6. Zar JH. Biostatistical analysis. Englewood Cliffs: Prentice Hall, 1984.

7. Fisher LD. Biostatistics a methodology for the health sciences. New York: WileyInterscience, 1993.

8. Nattie EE, Wiley CW, Bartlett Jr D. Adaptive growth of the lung following pneumonectomy in rats. J Appl Physiol 1974; 37:491-5.

9. Ruiz Jr RL, Curi PR, Cataneo AJM. Compensatory lung growth: lung mass and protein contents in trilobectomized rats. Acta Cir Bras 1996; 11:127-32.
10. Romanova LK, Leikina EM, Antipova KK. Nucleic acid synthesis and mitotic activity during development of compensatory hypertrophy of the lung in rats. Bull Exp Biol Med 1967; 63:303-6.

11. Fisher JM, Simnett, JD. Morphogenetic and proliferative changes in the regenerating lung of the rat. Anat Rec 1973; 176:389-96.

12. Rannels DE, White DM, Watkins CA. Rapidity of compensatory lung growth following pneumonectomy in adult rats. J Appl Physiol 1979; 46:326-33.

13. Ruiz Jr RL, Burini RC, Cataneo AJM. Compensatory lung growth: lung protein, DNA and RNA contents in trilobectomized rats. Acta Cir Bras 1998; 13:18-25.

14. Thet LA, Law DJ. Changes in cell number and lung morphology during early postpneumonectomy lung growth. J Appl Physiol 1984; 56:975-8.

\begin{abstract}
Ruiz Júnior RL, Carvalho LR, Cataneo AJM. Compensatory lung growth: body mass, protein content and lung mass in undernourished trilobectomized rats. Acta Cir Bras [serial online] 2004 Mar-Apr;19(2). Available from URL: http:/ /www.scielo.br/acb.

ABSTRACT - Purpose: To evaluate the biochemical behavior of compensatory lung growth after trilobectomy in undernourished rats. Methods: Undernutrition was achieved by offering 33\% normal daily diet to 137 adult male Wistar rats over an acclimatization period and throughout the experiment. Rats were randomly distributed into nine (3 Control, 3 Thoracotomy, and 3 Trilobectomy) groups. Analysis was 7, 30, and 90 days after surgery (Trilobectomy is middle, accessory and caudal lobectomies). Body mass, lung mass, and lung tissue protein content were studied. Results: Cranial lobe and left lung mass both larger in trilobectomized rats throughout the study compared to the other groups. Comparing combined lung mass, we noted that there was sufficient compensatory growth to be on a par with controls. Cranial lobe and left lung protein content in trilobectomized rats both displayed the same behavior as lung mass throughout the study, but the compensatory growth in the remaining two lobes was not sufficient to make up for trilobectomy losses. Conclusion: In adult undernourished rats, there was compensatory lung growth after trilobectomy, there was also lung mass recovery at the beginning of the study compared to other groups. Throughout the study, cranial lobe and left lung protein content were higher in trilobectomized rats than other groups.
\end{abstract}

KEY WORDS - Lung/growth and development. Nutricion disorders. Wistar rats.

Correspondência:

Prof. Dr. Raul Lopes Ruiz Jr.

Disciplina Cirurgia Torácica

Depto. de Cirurgia e Ortopedia

Fac. Med. Botucatu - UNESP

Tel/Fax: (14) 3815-7615

ruizraul@fmb.unesp.br

Conflito de interesse: nenhum

Fonte de financiamento: nenhuma

Data do recebimento: 19/12/2003

Data da revisão: 06/01/2004

Data da aprovação: 22/01/2004

*Agribrands Purina do Brasil Ltda. 